\section{AL-AZHAR Dental Journal}

F o r
The Official Publication of The Faculty of Dental

Medicine For Girls,

Al-Azhar University Cairo, Egypt.

Print ISSN 2537-0308 • Online ISSN 2537-0316

ADJ-for Girls, Vol. 8, No. 1, January (2021) - PP. 81:90

\title{
Patient Satisfaction, Retentive Characteristics and Masticatory Efficiency in Maxillary Single Denture Wearers with Different Denture Bases: A Randomized Crossover Clinical Trial
}

\section{Neveen S. Abd El Rahim ${ }^{1 *}$}

Codex : 10/21.01

azhardentj@azhar.edu.eg

http://adjg.journals.ekb.eg

DOI: $10.21608 /$ adjg. 2020.44524 .1299

Restorative Dentistry

(Removable Prosthodontics, Fixed

Prosthodontics, Endodontics, Dental Biomaterials, Operative Dentistry)

\section{KEYWORDS}

Single denture,

denture bases, patient

satisfaction, denture retention,

masticatory efficiency.

\begin{abstract}
Purpose: To evaluate patient satisfaction, the retentive characteristics, and the masticatory efficiency in maxillary single denture wearers with 3 different denture bases. Material and Methods: 40 patients; 10 dentate (control group (GC)) and 30 completely edentulous maxillary ridges patients (43-56 years) were selected for this study. The maxillary completely edentulous patients were divided into 3 groups randomly; 10 patients each and received single dentures; Group I (GI) received conventional heat cured acrylic resin (AR) followed by thermoplastic acrylic resin (TAR) then thermoplastic nylon (TN) denture base (GI:AR/TAR/TN), (GII:TAR/TN/ AR) and (GIII:TN/AR/TAR). Patient satisfaction, the retentive characteristics and the masticatory efficiency were evaluated 3 months after delivery of each single denture. Results: 27 out of 30 patients had age of (mean $50 \pm 3.7$ years) accomplished the study. Statistically significant differences were observed in comfort and appearance, $\mathrm{p} \leq 0.05$. No statistically significant differences were observed in phonetics, pain, or ease of cleaning of maxillary single denture, $p>0.05$. Statistically significant differences were observed in the retentive forces between (AR, TAR and TN), $\mathrm{p} \leq 0.05$ except between (TN and TAR), $p>0.05$. Statistically significant differences were observed in the masticatory efficiency between (GC, AR, TAR and TN), p $\leq 0.05$ except between (TAR and TN), $\mathrm{p}>0.05$. Conclusions: Maxillary single dentures with TN denture bases showed the advantage over TAR and AR denture bases in terms of comfort and appearance. Retention forces of TN and TAR were comparable and higher than that of AR denture bases. Type of denture base does not influence the masticatory efficiency of maxillary single denture wearers.
\end{abstract}

1. Assistant Professor of Removable Prosthodontics, Faculty of Dental Medicine for Girls, Al- Azhar University, Cairo, Egypt, Associate Professor of Removable Prosthodontics, College of Dentistry, Taibah University, Medina, Saudi Arabia.

* Corresponding author email: neveen20001@yahoo.com 


\section{INTRODUCTION}

Single denture (SD) is one of the removable appliances which attract the attention and be in mind of most of the dentists in an attempt to prolong the life of the remaining natural teeth and relating structures. The success of SD ultimately depends on a number of factors such as retention, stability, support, aesthetics, and masticatory function ${ }^{(1)}$.

Construction of SD is a demanding prosthetic procedure chiefly when opposed by natural teeth in non-harmonious occlusal plane. Normal occlusal plane is the goal of all prosthetic procedures to enable normal mandibular movements and masticatory efficiency ${ }^{(2)}$.

Various materials and designs are currently available to construct the bases of single dentures. Prostheses constructed from acrylic resins are frequently used to replace extracted teeth; since they are inexpensive and easily constructed. Advantages of polymethyl methacrylate (PMMA) include satisfactory aesthetic property, adequate conductivity to heat, permeability to fluids is low, colour durability and its dental processing procedure is clear. Although, it had the following disadvantages; law mechanical characteristics, entrance into undercut areas is difficult, fracture due to brittleness, polymerization shrinkage and allergy to its monomer ${ }^{(3-5)}$.

Thermoplastic denture base had been originated as substitute to conventional heat cured resin. Now, there are numerous types of thermoplastic resins, and their mechanical and physical characteristics are varied according to components ${ }^{(6)}$.

Polyamide is a thermoplastic resin denture base material which had low modulus of elasticity than conventional heat cured resins denture base, better denture adaptation as well as denture retention because of their light weight and because of engaging more desirable undercuts. These materials provide perfect aesthetics associated with easy processing and favourable physical characteristics. Despite its favourable aesthetic and more flexibility than acrylic resin, polyamide offered improper bond with self-cure resin, law flexural strength due to water sorption, and deformed excessively as a result of loading ${ }^{(7-9)}$.

While oral health related quality of life (OHRQoL) is considered as a valuable treatment option from patient's point of view, satisfaction of patient and preference of treatment should be considered during dental treatment. A questionnaire has been used subjectively in many studies for a subjective assessment of patient satisfaction, the feeling of retention, stability, a person's responses about chewing ability among patients with $\operatorname{SDs}^{(10,11)}$.

Complete denture retention and stability have been evaluated by numerous methods, such as kinesiography. Different objective methods were established to clarify the efficacy of SDs including occlusal force to determine denture stability and retention, dislodgment of denture to evaluate movement of denture during function and chewing efficiency and masticatory performance ${ }^{(12-14)}$.

The importance of evaluating chewing effectiveness, mainly related to complete and single denture rehabilitation, a wide variety of methods employed in the analysis of masticatory efficiency have been studied. For adequate masticatory performance test, the number of masticatory strokes of a food should be less than that of chewing strokes needed by a patient to prepare the same food to be swallowed ${ }^{(15)}$.

The most frequent patient complains with single dentures are those related to appearance, pain, difficulties during eating, stability, and retention. Retention is affected by physical, physiological, anatomical, mechanical, psychological, surgical, and retentive factors. The retention of a single denture is highly influenced by the accuracy of the base to the underlying basal tissues. The higher dimensional stability and accuracy of the denture base, the higher the adaptability to the underlying basal tissues and optimizing the retention ${ }^{(14,16)}$. 
Therefore, this clinical trial was planned to assess and compare patient satisfaction, the retentive characteristics and the masticatory efficiency in patients wearing maxillary single denture with conventional heat polymerized acrylic resin, thermoplastic acrylic resin and thermoplastic nylon denture bases.

The null hypotheses were; there would be no differences in patient satisfaction, the retentive characteristics and the masticatory efficiency of patients wearing maxillary single dentures with different denture bases.

\section{MATERIAL AND METHODS}

This crossover randomized clinical trial was carried out by selecting all patients from the outpatient clinic, Removable Prosthodontics Department, Faculty of Dental Medicine, Al- Azhar University- Girls' Branch. The selected patients had dentate maxillary and mandibular arches which considered the control group, $\mathrm{n}=10$ and maxillary ridges were completely edentulous and mandibular arches were dentulous or partially edentulous, $n=30$. The samples size was 40 patients, 21 females and 19 males, with age ranged between 43-56 years. Based on ren sults from previous studies, it was found that 28 casf es are enough for conducting the research at power 0.80, confidence interval 0.95 and alpha level 0.05; drop-out, $10 \%{ }^{(10,11)}$.

The inclusion and exclusion criteria for patients' selection were; they were selected in good general health and free from any systemic or local diseases, temporomandibular joint (TMJ) disorders or neuromuscular abnormalities. Patients had Angle's class I jaw relationship. Patients performing abnormal tongue habits, bruxism or clinching were excluded from this clinical trial to prevent the adverse outcomes on the oral functions and musculatures.

For completely edentulous maxillary ridges patients; they had sufficient inter-arch space, their maxillary edentulous ridges had adequate contour which covered with firm and healthy mucosa; free from inflammation, ulceration and flappy tissues. At least 6 months was elapsed from the last extracted tooth. They did not have any previous denture experience.

All patients have written informed consent approved by the university institutional review board (No. Al-Azhar University, Faculty of Dental Medicine Research Ethics Committee (AUFDREC)/019-001). Necessary periodontal, surgical, conservative, and prosthetic mouth preparations were carried out for the mandibular natural teeth. Ten dentulous patients were considered the control group (GC). The maxillary edentulous patients $(n=30)$ were randomized by order of arrival into three groups; ten patients' each. The $1^{\text {st }}$ group (GI): received heat cured acrylic resin (AR) followed by thermoplastic acrylic resin (TAR) followed by thermoplastic nylon (TN) denture base material for maxillary single dentures; (GI: AR/TAR/TN). The $2^{\text {nd }}$ group (GII) received (GII: TAR/TN/AR). The $3^{\text {rd }}$ group (GIII) received (GIII: TN/AR/TAR).

The principles of clinical and laboratory procedures were followed for construction of; conventional heat polymerized acrylic resin (Vertex-Dental BV.J.V., Zeist, Netherlands), thermoplastic acrylic (Polyan IC TM bredent GmbH \& Co.KG, Germany), and thermoplastic nylon Vertex $^{\mathrm{TM}}$ Thermo Sens, Vertex-Dental B.V. Netherlands) denture base materials in maxillary single dentures for maxillary edentulous patients. The finished and polished maxillary single dentures were delivered for GI, GII, and GIII and patients have been instructed to utilize their single dentures for a month as a minimal period for adaptation. Patient satisfaction, the retentive forces, and the masticatory efficiency were evaluated three months from delivery for all groups.

\section{1- Patient satisfaction}

A questionnaire was designed containing 5 questions regarding the following parameters: comfort, appearance, phonetics, pain, and ease of cleaning of maxillary single denture. All patients 
have been instructed to score these parameters of the denture on Likert scale with 5-point. The assessment was performed after the patient's utilization of each denture for three months. The assessment was carried out by the same examiner who was unaware of the group of the patient.

Statistical analysis of the differences between the three tested groups at the different post-insertion recalls was carried out during use of the single dentures.

\section{2- Retentive force measurements}

Retentive force was measured by a universal testing machine (Model 3345, Instron, England) had $500 \mathrm{~N}$ load cell which had a computer software to provide a vertical displacing force at $5 \mathrm{~mm} / \mathrm{min}$ cross- head speed for each denture from the vertical way. The retentive forces required to separate the dentures in GI, GII and GIII were measured three months after delivery of each maxillary single denture and the applied force was expressed in Newton (N). The machine was composed of attachment part, chin rest and universal testing machine. The patient has been guided to take a seat in straight posture and keep his chin precisely positioned on a chin support. The denture was firmly fixed to the bar and the attachment part of the universal machine was adjusted. A vertical dislodging force was related by the universal testing machine. The force was raised cautiously in a vertical direction till displacement of the denture appeared. The device was subjected to a slowly increasing vertical load $5 \mathrm{~mm} / \mathrm{min}$ until the denture was totally out of place. The dislodgment load recognized by an audible sound tuck and established by a sharp decrease at load-deflection curve measured using computer software (Bluehill Universal, Instron, England) and this value was measured in N. The trial was repeated five times to obtain 5 records, the mean of which was calculated. The retention force mean values obtained were recorded, tabulated and statistically analysed for each denture.

\section{3- The masticatory efficiency test}

The masticatory efficiency was evaluated for $\mathrm{GC}$, and after three months from maxillary single dentures delivery for GI, GII and GIII. 5 measures were assorted as patient was chewing equal pieces of $1 \mathrm{~cm}$ cube of banana and carrot and one grain of peanuts, as following, a: the number of masticating strokes till $1^{\text {st }}$ swallow; b: the number of masticating strokes till mouth empty of food; c: the number of swallowing till mouth empty of food; d: the time (in second) passed till $1^{\text {st }}$ swallow; e: the time (in second) passed till the mouth empty of food. Patient was guided to masticate food at ordinary speed and swallow at increments. These measurements were carried out while the patient was using the preferred side. The measurements were re-evaluated 3 times and the mean of the 3 measurements were rated as mean value of the masticatory efficiency for the patient $^{(11)}$.

\section{Statistical analysis}

For statistical analysis, SPSS 20 was used to analyse the computerized data. Shapiro-Wilk normality tests were carried out for constant variables and normally distributed data was disclosed. A mean value and standard deviation were used to represent the quantitative data. To clarify the significance of differences between two continuous variables, the independent student's t-test was utilized and between more than 2 groups, one-way ANOVA was used. The Likert-scale scores of denture-related parameters were analysed utilizing the Kruskal Wallis test. The results were found to be significant at $\mathrm{p}$-value $\leq 0.05$.

\section{RESULTS}

\section{Patients flow}

Forty patients, control group $(\mathrm{n}=10)$ and groups I, II and III $(n=30)$, were selected for this study. Two patients (a female and a male) in GI and a male patient in GII discontinued the follow up. Eventually, thirty-seven patients; GC $(n=10)$ and 
groups I, II and III ( $\mathrm{n}=27)$, with mean age $50 \pm 3.7$ years; $54 \%$ females $(n=20)$ and $46 \%$ males $(n=17)$ accomplished the study, figure 1 .

After three months from maxillary single dentures delivery, the patient satisfaction was evaluated using the Likert-scale scores ${ }^{(10)}$ for parameters of the denture; comfort, appearance, phonetics, pain, and ease of cleaning of maxillary single denture. Patients with thermoplastic nylon (TN) shows better scores followed by thermoplastic acrylic denture (TAR) and finally heat cured acrylic resin denture base material (AR); TN $>$ TAR $>$ AR. Regarding comfort; $82.8 \%$ of patients with TN denture bases rated their dentures as good or excellent, while TAR and AR denture bases $41 \%$ and $24.1 \%$ respectively. There was statistically significant difference between these groups, $\mathrm{p} \leq 0.05$. Also, for appearance; there was statistically significant difference between TN, TAR and AR, $\mathrm{p} \leq 0.05$. While for phonetics, pain, and ease of cleaning of maxillary single denture, there were no statistically significant difference between TN, TAR and AR, p>0 0.05, figure 2 .

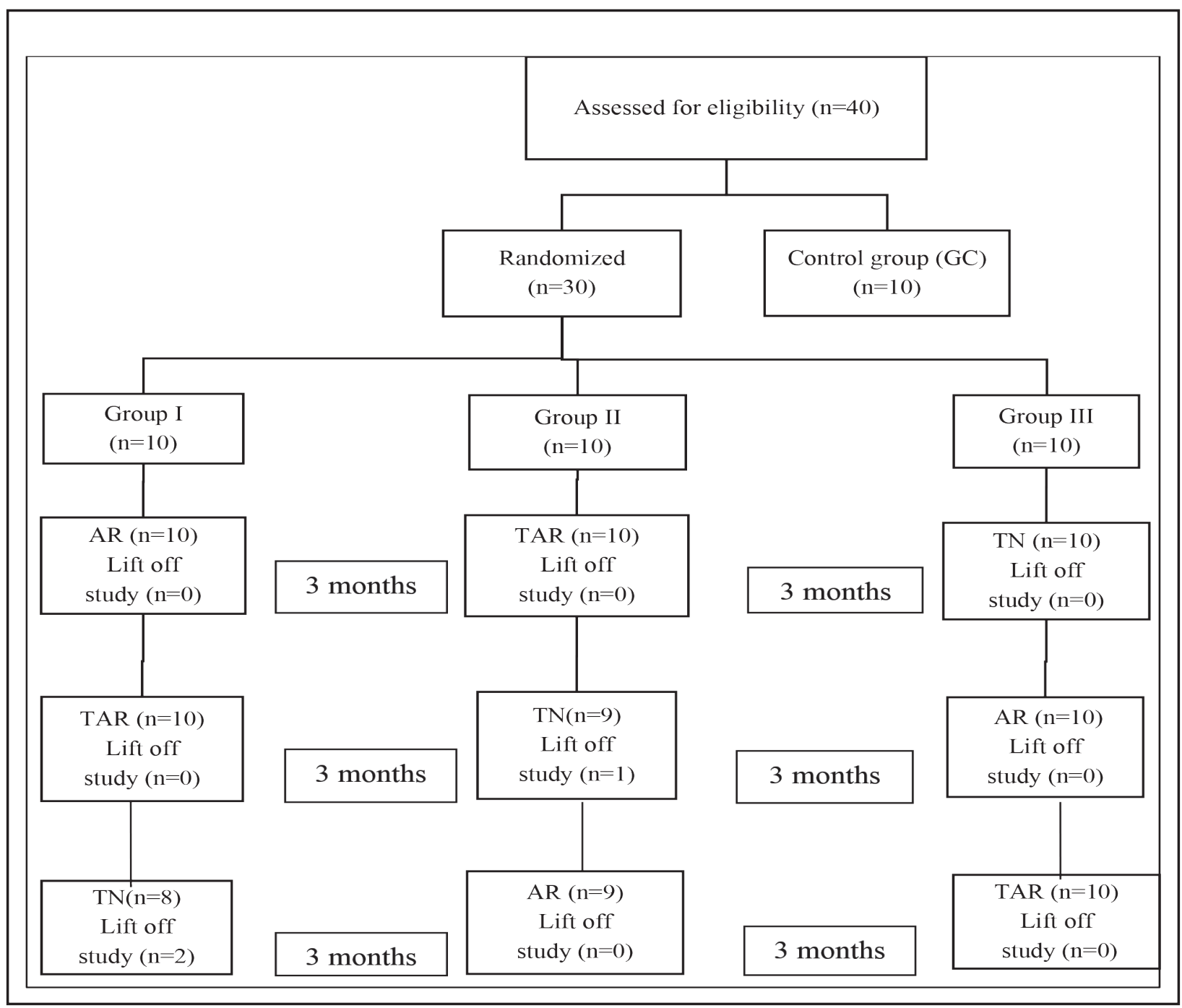

Figure(1) Diagram flow of clinical trials. 


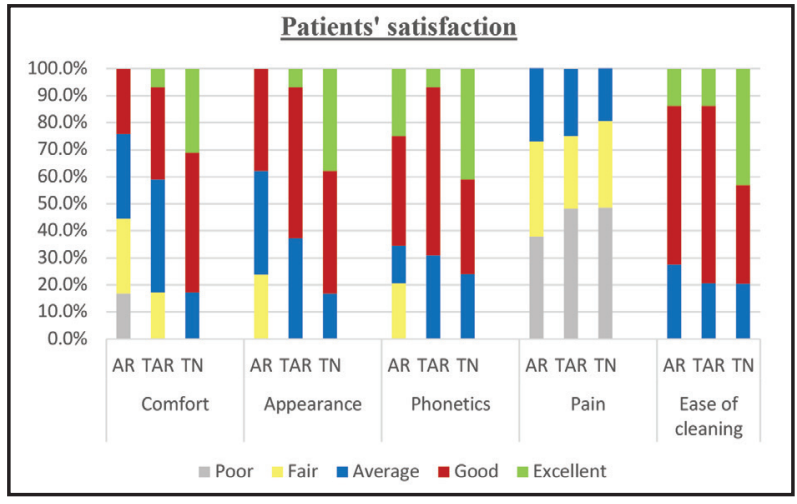

Figure (2): Denture related parameters in patients with AR, TAR and TN denture base materials for maxillary single dentures.

After three months from maxillary single dentures delivery, the retentive forces were the highest in TN followed by TAR and finally AR denture base; TN $>$ TAR $>$ AR. There was statistically significant difference between these groups, $\mathrm{p} \leq 0.05 \mathrm{ex}-$ cept between (TN and TAR), p>0.05, table 1 and figure 3.

Table (1): Retentive forces in different groups after 3 months.

\begin{tabular}{|c|c|c|c|c|}
\hline Groups & $\begin{array}{c}\text { AR } \\
(\mathbf{n}=\mathbf{2 7})\end{array}$ & $\begin{array}{c}\text { TAR } \\
(\mathbf{n}=\mathbf{2 7})\end{array}$ & $\begin{array}{c}\text { TN } \\
(\mathbf{n}=\mathbf{2 7})\end{array}$ & P-value \\
\hline Mean \pm SD & $7.10 \pm 1.17$ & $12.38 \pm 2.46$ & $14.05 \pm 2.34$ & $0.0001^{*}$ \\
\hline
\end{tabular}

SD, Standard deviation. * * Significant.

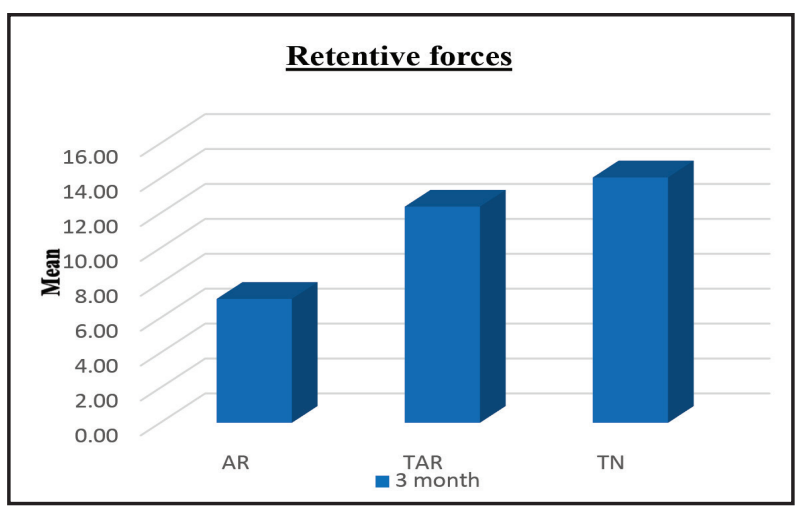

Figure (3): Mean values of retentive forces in AR, TAR, and TN after 3 months.
After three months from maxillary single dentures delivery, the masticatory efficiency was evaluated for AR, TAR, and TN. Five measures (A, B, C, $\mathrm{D}$ and $\mathrm{E}$ ) were recorded while patients were chewing banana, peanut and carrots. From table 2 and figure 4 , the following results could be achieved:

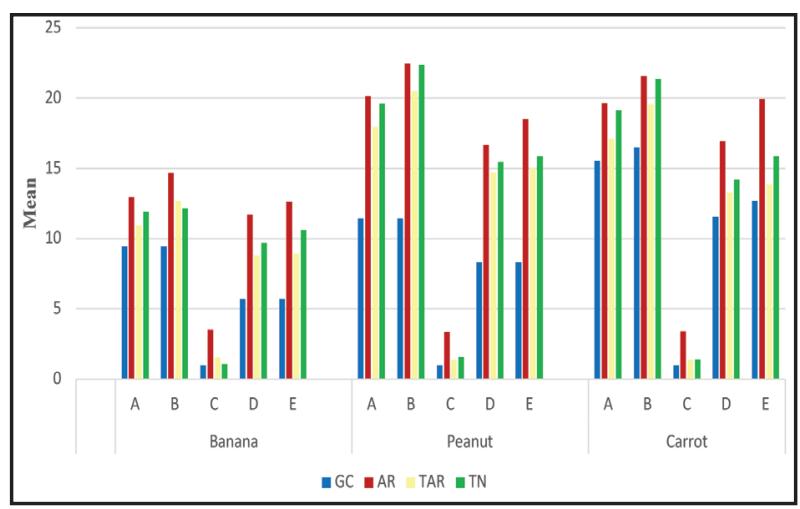

Figure (4): Masticatory efficiency (mean values) in the studied groups during chewing of banana, peanut and carrots.

Measure a: the number of masticating strokes till $1^{\text {st }}$ swallow during chewing of banana, peanut and carrot were ( $\mathrm{GC}<\mathrm{TAR}<\mathrm{TN}<\mathrm{AR})$. During chewing of banana, there was no statistically significant difference between groups, $\mathrm{p}>0.05$ except between ( $\mathrm{GC}$ and $\mathrm{AR}$ ) and (GC and TN), $\mathrm{p} \leq 0.05$. However, during chewing of peanut, there was statistically significant difference between groups, $\mathrm{p} \leq 0.05$ except between (AR and TAR), (AR and TN) and (TAR and TN), p $>0.05$. During chewing of carrot, there was no statistically significant difference between groups, $\mathrm{p}>0.05$ except between ( $\mathrm{GC}$ and $\mathrm{TN}), \mathrm{p} \leq 0.05$.

Measure $b$ : the number of masticating strokes till mouth empty of food during chewing of banana, peanut and carrot were $(\mathrm{GC}<\mathrm{TAR}<\mathrm{TN}<\mathrm{AR})$. During chewing of banana, there was no statistically significant difference between groups, $\mathrm{p}>0.05$ except between (GC and TN), and (GC and AR), $\mathrm{p} \leq 0.05$. During chewing of peanut, there was statistically significant difference between groups, $\mathrm{p} \leq 0.05$ except between (AR and TAR), (AR and $\mathrm{TN})$ and (TAR and TN), $\mathrm{p}>0.05$. During chewing 
of carrot, there was no statistically significant difference between groups, $\mathrm{p}>0.05$.

Measure c: the number of swallowing till mouth empty of food during chewing of banana, peanut and carrot were $(\mathrm{GC}<\mathrm{TN}<\mathrm{TAR}<\mathrm{AR}),(\mathrm{GC}<\mathrm{TAR}$ $<\mathrm{TN}<\mathrm{AR})$ and $(\mathrm{GC}<\mathrm{TAR}<\mathrm{TN}<\mathrm{AR})$ respectively. During chewing of banana, there was statistically significant difference between groups, $\mathrm{p} \leq 0.05$ except between (GC and TN), $p>0.05$. During chewing of peanut, there was statistically significant difference between groups, $\mathrm{p} \leq 0.05$ except between (TAR and $\mathrm{TN}), \mathrm{p}>0.05$. During chewing of carrot, there was statistically significant difference between groups was statistically significant, $\mathrm{p} \leq 0.05$ except between (TAR and TN)), $\mathrm{p}>0.05$.

Measure d: the time (in second) passed till $1^{\text {st }}$ swallow during chewing of banana, peanut and carrot was $(\mathrm{GC}<\mathrm{TAR}<\mathrm{TN}<\mathrm{AR})$. During chewing of banana, there was statistically significant difference between groups, $\mathrm{p} \leq 0.05$ except between (AR and
$\mathrm{TN}$ ), and (TAR and TN), $\mathrm{p}>0$ 0.05. During chewing of peanut, there was statistically significant difference between groups, $\mathrm{p} \leq 0.05$ except between ( $\mathrm{AR}$ and $\mathrm{TN}),(\mathrm{AR}$ and TAR), and (TAR and TN), $\mathrm{p}>0.05$. During chewing of carrot, there was no statistically significant difference between groups, $\mathrm{p}>0.05$ except between (GC and TAC), (GC and AR), and (GC and TN), $\mathrm{p} \leq 0.05$.

Measure e: the time (in second) passed till the mouth empty of food during chewing of banana, peanut and carrot was $(\mathrm{GC}<\mathrm{TAR}<\mathrm{TN}<\mathrm{AR})$. During chewing of banana, there was statistically significant difference between groups, $\mathrm{p} \leq 0.05$ except between (AR and TAR), and (TAR and TN), $p>0.05$. During chewing of peanut, there was statistically significant difference between groups, $\mathrm{p} \leq 0.05$ except between (AR and TN), (AR and TAR), and (TAR and TN), $p>0.05$. During chewing of carrot, there was no statistically significant difference between groups, $\mathrm{p}>0.05$ except between (GC and AR), $\mathrm{p} \leq 0.05$.

Table (2): Masticatory efficiency in different groups during chewing of (banana, peanut and carrot) after 3 months.

\begin{tabular}{|c|c|c|c|c|c|c|c|c|c|c|c|c|c|c|c|}
\hline \multirow{3}{*}{$\begin{array}{c}\begin{array}{c}\text { Test } \\
\text { food }\end{array} \\
\text { Groups }\end{array}$} & \multicolumn{15}{|c|}{ Masticatory efficiency $($ Mean \pm SD) } \\
\hline & \multicolumn{5}{|c|}{ Banana } & \multicolumn{5}{|c|}{ Peanuts } & \multicolumn{5}{|c|}{ Carrots } \\
\hline & $\mathbf{A}$ & $\mathbf{B}$ & $\mathbf{C}$ & D & $\mathbf{E}$ & $\mathbf{A}$ & B & $\mathbf{C}$ & D & $\mathbf{E}$ & $\mathbf{A}$ & $\mathbf{B}$ & $\mathbf{C}$ & D & $\mathbf{E}$ \\
\hline $\begin{array}{c}\text { GC } \\
(n=10)\end{array}$ & $\begin{array}{c}9.42 \\
\pm 2.89\end{array}$ & $\begin{array}{c}9.42 \\
\pm 2.89\end{array}$ & $\begin{array}{c}1 \\
\pm 0.01\end{array}$ & $\begin{array}{c}5.71 \\
\pm 1.81\end{array}$ & $\begin{array}{r}5.71 \\
\pm 1.8\end{array}$ & $\begin{array}{r}11.46 \\
\pm 3.32\end{array}$ & $\begin{array}{r}11.46 \\
\pm 3.32\end{array}$ & $\begin{array}{c}1 \\
\pm 0.01\end{array}$ & $\begin{array}{c}8.31 \\
\pm 2.38\end{array}$ & $\begin{array}{c}8.31 \\
\pm 2.38\end{array}$ & $\begin{array}{l}15.53 \\
\pm 3.55\end{array}$ & $\begin{array}{l}16.50 \\
\pm 4.48\end{array}$ & $\begin{array}{c}1 \\
\pm 0.01\end{array}$ & $\begin{array}{l}11.55 \\
\pm 1.56\end{array}$ & $\begin{array}{l}12.67 \\
\pm 1.95\end{array}$ \\
\hline $\begin{array}{c}\mathbf{A R} \\
(\mathbf{n}=\mathbf{2 7})\end{array}$ & $\begin{array}{l}12.93 \\
\pm 4.28\end{array}$ & $\begin{array}{l}14.67 \\
\pm 5.87\end{array}$ & $\begin{array}{c}3.5 \\
\pm 0.48\end{array}$ & $\begin{array}{r}11.70 \\
\pm 3.17\end{array}$ & $\begin{array}{l}12.61 \\
\pm 4.48\end{array}$ & $\begin{array}{l}20.15 \\
\pm 2.37\end{array}$ & $\begin{array}{l}22.43 \\
\pm 6.54\end{array}$ & $\begin{array}{c}3.37 \\
\pm 0.48\end{array}$ & $\begin{array}{r}16.68 \\
\pm 3.29\end{array}$ & $\begin{array}{r}18.49 \\
\pm 5.30\end{array}$ & $\begin{array}{r}19.63 \\
\pm 6.27\end{array}$ & $\begin{array}{l}21.57 \\
\pm 7.65\end{array}$ & $\begin{array}{c}3.40 \\
\pm 0.52\end{array}$ & $\begin{array}{l}16.91 \\
7.03 \pm\end{array}$ & $\begin{array}{r}19.91 \\
\pm 7.14\end{array}$ \\
\hline $\begin{array}{c}\text { TAR } \\
(\mathbf{n}=\mathbf{2 7})\end{array}$ & $\begin{array}{l}10.93 \\
\pm 4.28\end{array}$ & $\begin{array}{l}12.67 \\
5.88 \pm\end{array}$ & $\begin{array}{c}1.53 \\
0.48 \pm\end{array}$ & $\begin{array}{c}8.76 \\
\pm 2.20\end{array}$ & $\begin{array}{c}8.94 \\
\pm 2.26\end{array}$ & $\begin{array}{l}17.95 \\
\pm 2.71\end{array}$ & $\begin{array}{l}20.52 \\
\pm 4.08\end{array}$ & $\begin{array}{c}1.37 \\
\pm 0.48\end{array}$ & $\begin{array}{r}14.68 \\
\pm 3.07\end{array}$ & $\begin{array}{r}15.03 \\
\pm 3.69\end{array}$ & $\begin{array}{l}17.10 \\
\pm 6.01\end{array}$ & $\begin{array}{r}19.57 \\
\pm 7.65\end{array}$ & $\begin{array}{c}1.35 \\
\pm 0.47\end{array}$ & $\begin{array}{r}13.28 \\
\pm 1.33\end{array}$ & $\begin{array}{l}13.87 \\
5.89 \pm\end{array}$ \\
\hline $\begin{array}{c}\text { TN } \\
(\mathbf{n}=\mathbf{2 7})\end{array}$ & $\begin{array}{l}11.91 \\
\pm 1.74\end{array}$ & $\begin{array}{l}12.13 \\
\pm 1.90\end{array}$ & $\begin{array}{r}1.06 \\
\pm 0.21\end{array}$ & $\begin{array}{c}9.70 \\
\pm 3.17\end{array}$ & $\begin{array}{l}10.62 \\
\pm 4.45\end{array}$ & $\begin{array}{l}19.60 \\
\pm 5.31\end{array}$ & $\begin{array}{l}22.35 \\
\pm 3.44\end{array}$ & $\begin{array}{c}1.57 \\
\pm 0.65\end{array}$ & $\begin{array}{l}15.45 \\
\pm 3.89\end{array}$ & $\begin{array}{l}15.86 \\
\pm 4.88\end{array}$ & $\begin{array}{l}19.10 \\
\pm 6.01\end{array}$ & $\begin{array}{l}21.33 \\
\pm 6.77\end{array}$ & $\begin{array}{c}1.40 \\
\pm 0.52\end{array}$ & $\begin{array}{l}14.17 \\
\pm 4.57\end{array}$ & $\begin{array}{l}15.87 \\
\pm 5.89\end{array}$ \\
\hline P-value & $0.03 *$ & $0.02 *$ & $0.0001 *$ & $0.0001 *$ & $0.0001 *$ & $0.0001 *$ & $0.0001 *$ & $0.0001 *$ & $0.0001 *$ & $0.0001 *$ & $0.04 *$ & 0.08 & $0.0001 *$ & $0.02 *$ & $0.02 *$ \\
\hline
\end{tabular}

SD, Standard deviation.

\section{*, Significant.}




\section{DISCUSSION}

Maxillary single denture should be retentive to achieve its goals as speech, mastication, aesthetics, and patient comfort. To achieve such needed retention, the denture base should be an exact replica of the patient's mouth to allow for close adaptation of the denture to the tissues ${ }^{(2)}$.

This study considered three different denture base materials; conventional heat polymerized acrylic resin, thermoplastic acrylic resin and theri moplastic nylon denture bases and their effect on patient satisfaction, the retentive characteristics and the masticatory efficiency in patients wearing maxillary single denture.

Retention test was carried out utilizing a universal testing machine with a standardized accurate device for measuring retention. The retention device is very sensitive as when device's sensitivity increases, this increases the device ability to read the smaller values of forces thus giving accurate records ${ }^{(17)}$.

Questionnaire assessed the accommodation of patients to their newly constructed single dentures which is frequently an index for an accepted or rejected treatment results. Patient' comfort with the single denture is often identified requisite for accepted accommodation to newly constructed dentures.OHRQoLis measured by such a dependable and effective tool. Thus the questionnaire considers a valid tool during comparing main differences between varied nations and cultivations ${ }^{(18,19)}$.

Masticatory efficiency was chosen as the main indicator for sample proportions evaluation due to its recognized consequence on ingestion, diet taken and community habit. In the present study, food tested was conducted for each patient by comparing the number of masticating strokes, chewing times and number of swallows of a test food. This technique was preferred by many authors, as it had proved to be a valid measure of masticatory efficiency. In contrast to other techniques, it is practical, applicable for all types of food and allows patients to chew and swallow normally ${ }^{(15,20)}$.
This study compared three denture bases in the same patient in cross-over technique. Cross-over design had the following advantages over parallel design; it required a smaller sample size, overcame the biased results, allowed a controllable dental treatment and ethical outcomes.

Regarding the results of the current study, the first null hypothesis of no difference in denture related parameters was rejected for comfort and appearance while accepted for the phonetics, pain and ease of cleaning in patients wearing maxillary single dentures with different denture bases. Many patients considered the thermoplastic nylon to be comfortable and had satisfied appearance than both thermoplastic acrylic resin and the conventional dentures. These results might be due to the main components of materials of the denture base. These were matched with the study found that, patients evaluated flexible single dentures to be the most comfortable, aesthetical, and retentive dentures ${ }^{(10,20)}$.

However, statistically non-significant difference was found between the three denture bases regarding the phonetics, pain and ease of cleaning of maxillary single denture. This might be due to, the three tested denture bases had the same thickness thus no difference found between them on the phonetics. Also, after three months use of each type of denture base there would not be pain due to adaptation to denture bases. Surface roughness and difficult polishing is one of disadvantage of polyamide resin, so there was no difference between the three tested denture bases regarding the ease of cleaning. It was found that, patients should be more conscious about their dentures hygiene when denture base made of polyamide resin rather than heat polymerized $\operatorname{resin}^{(21,22)}$

The second null hypothesis of no difference in the retentive characteristics of the three different denture bases was rejected. Statistically significant differences in the retention were found between the three studied denture bases. This indicated that the retention of thermoplastic nylon and 
thermoplastic acrylic resin were better than that of heat polymerized acrylic resin denture bases. Both thermoplastic nylon and thermoplastic acrylic resin denture bases are stable and offered better denture adaptation as well as denture retention because of their light weight and due to engaging more desirable undercuts also exhibit excellent solvent, wear, and fatigue resistance ${ }^{(5,9)}$.

Although there was no statistically significant difference in the retention between thermoplastic nylon and thermoplastic acrylic resin denture bases. These findings were matched with the study found that, there were no differences between physical properties or colour stability of thermoplastic nylon and thermoplastic acrylic resin denture base resins ${ }^{(5)}$.

The third null hypothesis of no difference in the masticatory efficiency of patients wearing maxillary single dentures with different denture bases was rejected. Statistically significant difference was found between the dentate patients (control group) and the three tested denture bases in all measures of masticatory efficiency (A, B, C, D and F). These were matched with the study found that, masticatory function of the complete denture wearers is much less than that dentulous patients. Patient wearing complete dentures require seven times masticating strokes more than dentulous patient to decrease the diet to $50 \%$ of its initial particle proportions ${ }^{(12,23)}$.

Although, statistically non-significant difference was found between the three tested denture bases in all measures of masticatory efficiency (A, B, C, $\mathrm{D}$ and $\mathrm{F}$ ). These findings can be due to the main components of the materials of the different denture bases. The heat polymerized acrylic resin denture bases give a hard and stable base, minimally flex and deform during mastication and supply firm surfaces for the diet grinding.

These findings are in agreement with the results of study which found that no statistically significant difference for masticatory efficiency was exist in both dry and wet values of the weight in banana between the flexible and conventional dentures.
Also, it was reported that at the time of denture insertion, there was no significance difference in masticatory performance between patients with a thermoplastic acrylic denture and patients with a thermoplastic nylon denture ${ }^{(20,24)}$.

However, it was concluded that after six months of denture use, patients with a thermoplastic nylon denture have a higher masticatory performance and biting force than patients with a thermoplastic acrylic denture ${ }^{(20,25)}$.

In the present study, the follow-up period was short, so clinical studies with longer duration are needed to reinforce the results of the current study. Also, only the vertical dislodgement which was perpendicular to the occlusal plane was evaluated, so that occlusal and mastication forces acting on maxillary single dentures in function could not be precisely simulated as.

\section{CONCLUSIONS}

Within the parameters of this study design: Maxillary single dentures with thermoplastic nylon denture bases revealed advantage over thermoplastic acrylic resin and conventional heat polymerized acrylic resin denture bases in terms of comfort and appearance. Retention forces of thermoplastic nylon and thermoplastic acrylic resin were comparable and higher than that of conventional heat polymerized acrylic resin denture bases. Type of denture base does not influence the masticatory efficiency of maxillary single denture wearers.

\section{REFERENCES}

1. Bhushan P, Aras MA, Chitre V, Mysore AR, Mascarenhas K, Kumar S. The Hollow Maxillary Complete Denture: A Simple, Precise, Single-Flask Technique Using a Caramel Spacer. J Prosthodont. 2019;28:e13-7.

2. Foong KW, Patil PG. Fabrication of maxillary single complete denture in a patient with deranged mandibular occlusal plane: A case report. Saudi Dent J. 2019;31: 148-54. 
3. Akinyamoju CA, Dosumu OO, Taiwo JO, Ogunrinde TJ, Akinyamoju AO. Oral health-related quality of life: Acrylic versus flexible partial dentures. Ghana Med J. 2019;53:163-9.

4. Palaskar J, Mittal S, Singh S. Comparative evaluation of surface porosities in conventional heat polymerized acrylic resin cured by water bath and microwave energy with microwavable acrylic resin cured by microwave energy. Contemp Clin Dent. 2013;4:147.

5. Song SY, Kim KS, Lee JY, Shin SW. Physical properties and color stability of injection-molded thermoplastic denture base resins. J Adv Prosthodont. 2019;11:32-40.

6. Fueki K, Ohkubo C, Yatabe M, Arakawa I, Arita M, Ino $\mathrm{S}$, et al. Clinical application of removable partial dentures using thermoplastic resin. Part II: Material properties and clinical features of non-metal clasp dentures. J Prosth Res. 2014;58:71-84.

7. Fueki K, Ohkubo C, Yatabe M, Arakawa I, Arita M, Ino S, et al. Clinical application of removable partial dentures using thermoplastic resin-Part I: Definition and indication of non-metal clasp dentures. J Prosthodont Res. 2014;58:3-10.

8. Wadachi J, Sato M, Igarashi Y. Evaluation of the rigidity of dentures made of injection-molded materials. Dent Mater J. 2013;32:508-11.

9. Nasution H, Kamonkhantikul K, Arksornnukit M, Takahashi H. Pressure transmission area and maximum pressure transmission of different thermoplastic resin denture base materials under impact load. J Prosthodont Res. 2018;62:44-9.

10. Fueki K, Yoshida-Kohno E, Inamochi Y, Wakabayashi N. Patient satisfaction and preference with thermoplastic resin removable partial dentures: a randomised cross-over trial. J Prosthodont Res. 2020;64:20-5.

11. Torres-Sánchez C, Montoya-Salazar V, Torres-Lagares D, Gutierrez-Pérez JL, Jimenez-Castellanos E. Satisfaction in complete denture wearers with and without adhesives: A randomized, crossover, double-blind clinical trial. J Clin Exp Dent. 2018;10:e585-90.

12. Torres-Sánchez C, Montoya-Salazar V, Torres-Lagares D, Gutierrez-Pérez JL, Jimenez-Castellanos E. Comparison of masticatory efficacy among complete denture wearers with two adhesives and dentate individuals: A randomized, crossover, double-blind clinical trial. J Prosthet Dent. 2017;117:614-20.

13. Tarkowska A, Katzer L, Ahlers MO. Assessment of masticatory performance by means of a color-changeable chewing gum. J Prosthodont Res. 2017;61:9-19.
14. Von der Gracht I, Derks A, Haselhuhn K, Wolfart S. EMG correlations of edentulous patients with implant overdentures and fixed dental prostheses compared to conventional complete dentures and dentates: a systematic review and meta-analysis. Clin Oral Implants Res. 2017;28:765-73.

15. Witter DJ, Woda A, Bronkhorst EM, Creugers NHJ. Clinical interpretation of a masticatory normative indicator analysis of masticatory function in subjects with different occlusal and prosthodontic status. J Dent. 2013;41:443-8.

16. Ogawa T, Sato Y, Kitagawa N, Nakatsu M. Relationship between retention forces and stress at the distal border in maxillary complete dentures: Measurement of retention forces and finite-element analysis in individual participants. J Prosthet Dent. 2017;117:524-31.

17. Bogucki ZA. Denture adhesives' effect on retention of prostheses in patients with xerostomia. Adv Clin Exp Med. 2018;27:1247-52.

18. Fayad MI. Oral Health Impact Profile in Edentulous Patients Rehabilitated With Conventional and Flexible Complete Denture. Egyption Dent J. 2016;62:1-8.

19. Al-Imam H, Özhayat EB, Benetti AR, Pedersen AML, Gotfredsen K. Oral health-related quality of life and complications after treatment with partial removable dental prosthesis. J Oral Rehabil. 2016;43:23-30.

20. Hazari P, Bhoyar A, Mishra SK, Yadav NS, Mahajan H. A comparison of masticatory performance and efficiency of complete dentures made with high impact and flexible resins: A pilot study. J Clin Diagnostic Res. 2015;9:ZC29-34.

21. Fueki K, Yoshida-Kohno E, Wakabayashi N. Oral healthrelated quality of life in patients with non-metal clasp dentures: a randomised cross-over trial. J Oral Rehabil. 2017;44:405-13.

22. Ito M, Wee AG, Miyamoto T, Kawai Y. The combination of a nylon and traditional partial removable dental prosthesis for improved esthetics: A clinical report. J Prosthet Dent. 2013;109:5-8.

23. Hama Y, Kanazawa M, Minakuchi S, Uchida T, Sasaki Y. Properties of a color-changeable chewing gum used to evaluate masticatory performance. J Prosthodont Res. 2014;58:102-6.

24. Neveen A. Effect of Different Denture Base materials on Masticatory Efficiency and Retention of Complete Denture. Egypt Dent J. 2016;62:1721-8.

25. Fayad M, Harby N. Masticatory Performance and Bite Force Evaluation in Completely Edentulous Patients Rehabilitated With Different Thermoplastic Denture Base Materials. Egypt Dent J. 2017;63:1861-9. 